\title{
LIBERTARIAN FREEDOM AND THE AVOIDABILITY OF DECISIONS
}

\author{
David Widerker
}

\begin{abstract}
Recently, John Fischer has applied Frankfurt's well-known counter-example to the principle of alternate possibilities to refute the traditional libertarian position which holds that a necessary condition for an agent's decision (choice) to be free in the sense of freedom required for moral responsibility is that the decision not be causally determined, and that the agent could have avoided making it. Fischer's argument has consequently led various philosophers to develop libertarian accounts of freedom which try to dispense with the avoidability constraint on freedom. My purpose in this article is to show that Fischer's attack on traditional libertarianism fails, and, therefore, it is premature to abandon that position.
\end{abstract}

Is it possible for an agent to be morally responsible for a certain decision of his, even though that decision was unavoidable? An affirmative answer to this question would refute the traditional libertarian position which holds that a necessary condition for a decision (choice) to be free in the sense of freedom required for moral responsibility is that the decision not be causally determined, and that the agent could have avoided making it. Recently, such a refutation of libertarianism has been attempted by John Fischer ([1], pp.33-4) who bases his argument upon Harry Frankfurt's well-known counterexample to the principle of alternate possibilities

(PAP) A person is morally responsible for what he has done only if he could have acted otherwise [3].

Fischer's argument has consequently led philosophers such as Eleonore Stump and Norman Kretzmann ([6]; [7], p.398-99), Linda Zagzebski ([8], p.161) and Fischer himself ([1], p.34]) to develop alternative libertarian accounts of freedom which try to dispense with the avoidability constraint on freedom. My purpose in this article is to show that Fischer's Frankfurt-type attack on traditional libertarianism fails, and, therefore, it is premature to abandon this position.

To argue his point, Fischer asks us to consider the following scenario:

Black is a nefarious neurosurgeon. In performing an operation on Jones to remove a brain tumor, Black inserts a mechanism into Jones's brain which enables Black to monitor and to control Jones's activities. Jones, meanwhile knows nothing of this. Black exercises his control through a computer which 
he has programmed so that, among other things, it monitors Jones's voting behavior. If Jones shows an inclination to decide to vote for Carter, then the computer through the mechanism in Jones's brain, intervenes to assure that he actually decides to vote for Reagan and does so vote. But if Jones decides on his own to vote for Reagan, the computer does nothing but continues to monitor-without affecting-the goings-on in Jones's head. [Assume also that in the situation under consideration Jones cannot avoid performing one of these acts, that is he must decide either to vote for Carter or for Reagan and cannot remain undecided. ([1], p.25)] Suppose that Jones decides to vote for Reagan on his own, just as he would have if Black had not inserted the mechanism into his head. ([1], p.26)

Fischer claims that in this situation Jones can be said to be morally responsible for his decision to vote for Reagan, although he could not have refrained from it. And this is so, even if one assumes that the actual sequence issuing in the decision proceeds, as libertarians require, in a non-deterministic way, i.e., even if his decision is not causally determined.

....nothing about Frankfurt's example requires the actual sequence issuing in the decision and action to proceed in a deterministic way; if it proceeds in a non-deterministic way that satisfies the libertarian, then Jones can be held responsible, even though he could not have done otherwise. ([1], p.33)

I would like to disagree with this claim by Fischer.

Consider the proposition

(1) It was within Jones's power at $\mathrm{T}$ to decide to vote for Carter, $\mathrm{T}$ being a time-moment shortly before Jones decides to vote for Reagan in the real world.

Why does Fischer think that (1) is false? He must be reasoning as follows. Suppose that (1) were true. If so, we can conceive of a possible world identical in all relevant respects with the real world up until $\mathrm{T}$, in which Jones exercises his power to decide to vote for Carter. But since, ex hypothesi, Jones would in such a world show an inclination to decide to vote for Carter, the mechanism in his brain would intervene and force him to decide to vote for Reagan nevertheless. Hence the assumption that (1) is true leads to contradiction. Q.E.D.

Note that this reductio argument is sound only if we assume that

(2) Jones's showing an inclination to decide to vote for Carter is (in the circumstances) a causally necessary condition of his deciding to vote for the latter.

Otherwise, there is the distinct possibility of Jones's deciding to vote for Carter, even if previously he was inclined to decide not to vote for him. After all, as libertarians emphasize, free agents can sometimes choose or decide contrary to their inclinations. And in such a case the mechanism would not operate. But (2) implies that 
(3) Jones's not showing an inclination to decide to vote for Carter is (in the circumstances) causally sufficient for his not deciding to vote for the latter. ${ }^{1}$

Moreover, since Jones in fact did not show an inclination to decide to vote for Carter, we are led to the conclusion that Jones's not deciding to vote for Carter was causally determined, and thus, that his actual decision to vote for Reagan was causally determined as well. For ex hypothesi, if Jones does not decide to vote for Carter, he must decide to vote for Reagan. This conclusion, however, contradicts Fischer's explicit assumption as to Jones's decision to vote for Reagan not being causally determined. ${ }^{2}$

Discussing an objection whose conclusion is similar to the one stated above, Fischer counters that it would not show that Jones's decision is causally determined, since to have this feature the decision would have to be a final member of a sequence of events each of which is nomologically inevitable [1, pp.35-37]. (Roughly speaking, according to Fischer, an event E occurring at a time $\mathrm{T}$ is said to be nomologically inevitable at $\mathrm{T}$ just in case its occurrence is nomologically necessary at $\mathrm{T}$ in the sense that the proposition that $\mathrm{E}$ occurs at $\mathrm{T}$ is entailed by some conjunction of (true) propositions describing the laws of nature and events prior to $\mathrm{T}^{3}$ ) Clearly the objection I raise does not establish this stronger result. All it shows is that Jones's decision was nomologically inevitable, or that there was a condition that was causally sufficient for its occurrence. But note that Fischer is using "causally determined' in a non-standard and too strong sense which certainly would not be acceptable to the libertarian. According to the standard definition of this term, an event is causally determined iff there obtains prior to its occurrence a causally sufficient condition for it, or its occurrence is nomologically necessary at $\mathrm{T}$, in the sense specified above. The event need not be the "final member of a sequence of events each of which was nomologically inevitable." So for example, if $\mathrm{X}$ freely induces in $\mathrm{Y}$ an irresistible desire to perform a certain act, Y's act, according to the libertarian, would be considered causally determined, even though it results from an event which is not nomologically inevitable. Hence, this response by Fischer is unsatisfactory. ${ }^{4}$

However, another response to my criticism of Fischer could be given. It might be argued that my criticism rests on a mistaken assumption about the relation between an agent's decision to perform some act and his inclination to decide to perform it. The latter, one might claim, does not precede the decision, and thus is not a causally necessary condition for it, but is rather a part of it. In other words, a decision to do A, according to the objector, is a temporal process that begins with an inclination to decide to do A, and is then followed by some appropriate set of mental events which taken together make up the decision. This being the case, (2) is false, and hence Fischer's objection remains intact. However, this attempt, to rescue Fischer's attack on 
libertarianism would be unconvincing for two reasons. First, it would push the debate between Fischer and the libertarian only one step back. For instead of claiming that a free agent has it within his power to decide otherwise, the libertarian will insist now that such an agent has it within his power to form an inclination to decide otherwise. Secondly, and more importantly, the libertarian might reject the objector's conception of what a decision consists in. He might claim that a decision being the forming of an intention is a simple mental act that does not exhibit the sort of complex structure assumed by the objector. ${ }^{5}$ This point, he might stress, is also borne out by our every day talk about decisions. Thus, it would be conceptually wrong for one to describe what Jones is doing at a given moment by saying that he is in the process of deciding to vote for Reagan, or that he has not finished yet his decision to vote for Reagan. To be sure, Jones can be said to be in the process of trying to reach a decision as to whether to vote for Reagan or not. But that process and the event of deciding to vote for Reagan are two different things.

Fischer may yet have another argument for the falsity of (1). He may argue as follows:

(4) Either Jones shows at $\mathrm{T}$ an inclination to decide to vote for Reagan, or he does not.

(5) If he does show such an inclination, then Jones will decide at time $\mathrm{T}+\mathrm{i}$ to vote for Reagan.

(6) If he does not, then he will be forced by the mechanism to decide to vote for Reagan at that time.

Hence, in every causally possible future relative to $\mathrm{T}$, Jones decides at time $\mathrm{T}+\mathrm{i}$ to vote for Reagan, in which case his actual decision at $\mathrm{T}+\mathrm{i}$ to vote for Reagan is unavoidable. (Here $\mathrm{T}+\mathrm{i}$ is the exact time at which Jones decides to vote for Reagan in the actual world.)

But this argument, too, falls short of proving Fischer's point, according to the libertarian. To see this, let us examine (5) more closely. Note that the truth of it cannot be grounded in the fact that Jones's inclination to vote for Reagan is causally sufficient for his decision to vote for him, since such an assumption would not be accepted by the libertarian. On the other hand, if (5) is not thus construed, then the following two options are available to the libertarian to resist the contention that Jones's decision at $T+i$ of voting for Reagan is unavoidable. He may either reject (5), claiming that the most that he would be prepared to allow is

(5a) If Jones shows an inclination at $\mathrm{T}$ to decide to vote for Reagan, then Jones will probably decide at $\mathrm{T}+\mathrm{i}$ to vote for Reagan. (Cf. [5], p.111)

However, (5a) is compatible with Jones's having the power not to decide to vote for Reagan, since there is the possibility of Jones's acting out of char- 
acter. Or, he may construe (5) as a conditional of freedom in Plantinga's sense ([4], chap. 9), i.e., as

(5b) If Jones shows an inclination at $\mathrm{T}$ to decide to vote for Reagan, then Jones will freely decide at $\mathrm{T}+\mathrm{i}$ to vote for Reagan,

in which case, the libertarian may again claim that in the actual situation, when Jones shows an inclination to decide to vote for Reagan, he has it within his power not to decide to vote for Reagan. To be sure, as things turned out he did not exercise that power, but this fact is irrelevant. Thus, in either case Jones's power not to decide to vote for Reagan is preserved. Note that in case a libertarian construes (5) in terms of (5b), Black can, if he knows (5b), ensure that Jones will decide to vote for Reagan by inserting the mechanism in Jones's brain. However, if he acts in this way, he does not deprive Jones of his freedom to decide otherwise. He does not do this anymore than someone knowing that if he asks me what time it is, then I will freely tell him the time, can, by asking me this question, deprive me of my power not to answer his question.

I conclude that Fischer has failed to describe a scenario where a decision for which an agent is morally responsible is both causally undetermined and unavoidable. Hence, his Frankfurt-type attempt to refute traditional libertarianism does not succeed. ${ }^{6,7}$

Bar-Ilan University

\section{BIBLIOGRAPHY}

[1] John M. Fischer, "Responsibility and Control," The Journal of Philosophy, vol. 89 (1982), pp. 24-40. Reprinted in [2].

[2] John M. Fischer (ed.), Moral Responsibility (Cornell University Press, 1987).

[3] Harry Frankfurt, "Alternate Possibility and Moral Responsibility," The Journal of Philosophy, vol. 66 (1969), pp. 829-39. Reprinted in [2].

[4] Alvin Plantinga, The Nature of Necessity (Oxford University Press, 1974).

[5] Robert Adams, "Middle Knowlledge and the Problem of Evil," American Philosophical Quarterly, vol. 14 (1977), pp.109-17.

[6] Eleonore Stump, "Intellect, Will and the Principle of Alternate Possibilities, in Michael Beaty (ed.), Christian Theism and the Problems of Philosophy (Notre Dame: University of Notre Dame Press, 1990).

[7] Eleonore Stump and Norman Kretzmann, "Prophecy, Past Truth, and Eternity," Philosphical Perspectives, vol. 5 (1991).

[8] Linda Zagrzebski, The Dilemma of Freedom and Foreknowledge (Oxford: Oxford University Press, 1991). 


\begin{abstract}
NOTES
1. For if $\mathrm{p}$ is a causally necessary condition for $\mathrm{q}$, then $\mathrm{p}$ being absent is causally sufficient for $\mathrm{q}$ being absent.

2. Note that this argument can be easily extended so as to apply also to other indicators or signs of a person's decision than her inclination to make that decision. E.g., Frankfurt $[3$, p.835] mentions the possibility of a facial twitch of a person being such an indication.

3. Fischer's own definition of nomological inevitability [1, p. 35] is slightly different, but this difference can be safely ignored.

4. Fischer's point would be well taken if by stating my objection I wished to defend the thesis that (i) an agent is morally responsible for a decision of his only if that decision was avoidable, where 'morally responsible' in (i) is intended to cover also cases of derivative responsibility. For even if Jones's decision is causally determined, he may still be derivatively responsible for it, by being responsible for the state of affairs which was causally sufficient for it. But my refutation of his counterexample only concerned itself with a case in which the agent's decision was not causally determined. After all, this is the case which is crucial for the assessment of libertarianism. When 'morally responsible' is understood to in a derivative sense, libertarians would agree that a thesis such as (i) is false.
\end{abstract}

5. Note that this consideration would not hold for complex actions such as votings, killings, intentional omissions, etc. which, in addition to the volitional element typically involved in an action (volition, intention in action, etc.), also consist of other events.

6. For a defence of a different version of libertarianism against Frankfurt-type examples, one which makes use of the controversial notion of agent-causation, see Rowe [9, pp. 82-85].

7. I would like to thank Dale Gottlieb, Jerome Gellman, Bernard Katz, and most especially Charlotte Katzoff, Eddy Zemach and a referee of Faith and Philosophy, for excellent comments on an earlier version of this paper. 